\title{
Biohydrogen production deserves serious funding
}

One of the truisms of either basic or applied science is that a field never reaches its true potential until it organizes itself around some major project. Molecular biology has found it with the Human Genome Project. Unless there is a combination of money and basic science challenge, no matter how promising or worthy an area of endeavor, it will languish for lack of focus.

This seemed to be the case for a dedicated cadre of researchers attending the recent "Eighteenth Symposium on Biotechnology for Fuels and Chemicals," held in Gatlinburg, TN. An annual meeting that rotates its hosts-and location-between the Oak Ridge National Laboratory (ORNL, Oak Ridge, TN) and the National Renewable Energy Laboratory (Golden, CO), the meeting is meant to showcase current research on the production of renewable energy resources and bioremediation. With the exception of one presentation, what was remarkable was that, given the meeting's mandate, no basic precepts of science were challenged nor was the economic feasibility of any single project addressed. Presenter after presenter explained his or her research by echoing the words of one straightforward speaker, "I have a solution in search of a problem."

A notable exception was a presentation by Elias Greenbaum (ORNL) outlining his group's research on the production of hydrogen from the unicellular green algae, Chlamydomonas reinhardtii. In a paper published last August in Nature (376:438-431, 1995), Greenbaum's group showed that the B4 mutant is deficient in the membrane-bound photosystem I reaction center-but is still capable of performing complete photosynthesis. Until this demonstration, dogma had it that the conversion of light energy to chemical energy required both photosystem I and photosystem II reaction centers. The significance of this discovery is that, in principle, one should be able to double the maximum theoretical conversion rate of light to chemical energy from 10 to $20 \%$. Since these mutant algae are capable of synthesizing hydrogen without the participation of $\mathrm{CO}_{2}$ fixation, Greenbaum's group has proposed that they might be used to create a commercially viable hydrogen-production method. At present, the coproduction of oxygen with the hydrogen obviously means that an additional scheme needs to be developed to separate these potentially combustive gases.

This month in Nature Biotechnology, one more step in establishing hydrogen as a potentially viable energy source is presented. In a paper by Woodward et al. (p.872), researchers working in Greenbaum's group define an in vitro enzymatic pathway for hydrogen production based on the oxidation of glucose. The paper demonstrates a method of producing hydrogen from a renewable source, and the economics of the system seem to make it commercially attractive as well. One possibility is to use corn syrup-currently selling for $\$ 0.08$ per pound--as the glucose source and to sell the hydrogen byproduct. Alternatively, the glucose source might be some of the 16 billion pounds of cellulose generated each year in the United States from recycled newspapers. The authors calculate that, in theory, their in vitro process could convert this wastepaper stream into enough hydrogen to replace the annual natural gas energy demands of 37 cities the size of Oak Ridge, with its 27,000 inhabitants.

Taken together, these two papers present a solid combination of important basic science and feasible economic application. This research raises the question, "Is it time for a more serious national energy policy directed at biohydrogen production?" The advantages of hydrogen as a fuel are numerous: It is clean, efficient, renewable, and generates no toxic byproducts. The fact that the US space program has relied on hydrogen as a fuel for nearly 40 years provides a knowledge base from which "civilian" uses of the fuel could be derived - and technology transfer out of space program and into the private sector has been relatively successful. The US Department of Energy (Washington, DC) has a \$14-15 million hydrogen research and development (R\&D) program, of which about $\$ 1$ million is devoted to biohydrogen R\&D. This could be stepped up-the Japanese government and industry, to give one example, spend upward of $\$ 5$ million on biohydrogen research. The development of a commercially viable biohydrogen production system is the type of combined government/industry project that could bring biotechnology to the realization of an even larger potential than healing individuals-healing the planet itself.

\section{"B" ark lands at BIO}

In Douglas Adams's The Restaurant at the End of the Universe, the population of a doomed planet believed (by some of its inhabitants) to be in imminent danger of being eaten by an enormous star goat was put on board three spacecraft. The " $A$ " ship sparkled with all the brilliance of leadership-in business, politics, art, culture, and science. The " $\mathrm{C}$ " ark contained "all the people who did the actual work, who made things and did things." Everyone else-millions of lawyers, TV producers, personnel officers, management consultants, and other middlemen-were placed in suspended animation on the " $B$ " ark.

The "B" ark landed-it would appear-at BIO '96, the Biotechnology Industry Organization's (Washington, DC) annual gabfest, held this year in mid-June in Philadelphia. The five-day meeting attracted about 3500 participants from 30 countries. Some $45-50 \%$ of the registered delegates were biotechnology's middlemen: venture capitalists, patents lawyers, tax avoidance specialists, clinical trials organizers, deal facilitators, public relations advisors, stock analysts, regional development administrators, regulators, technology transfer staff, headhunters, and - of course-journalists. Most of them were drawn by the \$6-7 billion in new money that had come into biotechnology companies from investors during the first five months of this year.

The difference between the doomed planet and biotechnology, of course, is that biotechnology needs its middlemen. Biotechnology is a consortium of codependent organisms, each occupying a special and necessary niche on the path toward product development and profit generation. Our informal survey of the delegate list at BIO '96 was accompanied by some equally informal observations: the bonhomie and free lunches suggested that, for the moment, the supply of external expertise eager to tend to the needs of biotechnology greatly outstrips demand. Perhaps now is a good time for up and coming biotechnology companies to shop around for the external advice and services they need to bring their products along to market. Judging by the plethora of expertise present at BIO '96, there are bargains to be had. III 